\title{
Dynamic control for the separation of organic acids in capillary electrophoresis
}

\author{
Ming-Mu Hsieh, Huan-Tsung Chang* \\ Department of Chemistry, National Taiwan University, Taipei, Taiwan
}

Received 24 April 1997; received in revised form 7 July 1997; accepted 28 August 1997

\begin{abstract}
A new and very simple technique has been developed in capillary zone electrophoresis for the separation of organic acids. In this new method, capillaries were simply treated with $0.1 \mathrm{M} \mathrm{NaOH}$ via high pressure for $3 \mathrm{~min}$, then flushed with running buffer solutions via high pressure for $10 \mathrm{~s}$ before performing separation. After this treatment, electroosmotic flow (EOF) is higher than electrophoretic mobilities (EPM) of all analytes in weak acidic conditions. Thus, eight organic acids are well separated in less than $7 \mathrm{~min}$ at an applied voltage of $22 \mathrm{kV}$. In addition to significant differences of EPM among analytes in weak acidic conditions, dynamic changes in EOF and $\mathrm{pH}$ account for the good separation results. Capillary dimensions, ionic strength and type of buffer solution all show dramatic effects on the separations of organic acids. The results also support the existence of dynamic changes in the system during a run. This new method provides the advantages of reproducibility, speed and simplicity for the separation of organic acids which cannot be easily separated in the range of $\mathrm{pH} 4-6$ by any conventional means. (C) 1998 Elsevier Science B.V.
\end{abstract}

Keywords: Buffer composition; Electroosmotic flow; Electrophoretic mobility; Organic acids

\section{Introduction}

Capillary zone electrophoresis (CZE) has played an important role in modern separation science because of its high efficiency for almost any analyte [1-3]. However, there are some difficulties in the separation of organic acids under isocratic conditions because of the wide range of dissociation constants $\left(K_{\mathrm{a}}\right)$ among organic acids [4-6]. To overcome this problem, many useful methods have been reported in CZE [7,8]. Generally, control of the factors governing electrophoretic mobilities (EPM) of analytes and electroosmotic flow (EOF) is a typical choice to

\footnotetext{
${ }^{*}$ Corresponding author.
}

improve the separation resolution and shorten the separation time in CZE.

Many approaches have been suggested for controlling EOF in CZE. These include use of organic solvents [9], coating of the capillary wall [10], addition of surfactants [11], adding salts [12], application of an external electric field [13]. Field-amplification in CZE is also a good approach to control EOF and to obtain stacking effects inside the capillary [14]. More recently, self-regulating dynamic control of EOF by simply performing the separation with running buffers containing different concentrations of cetyltrimethylammonium bromide (CTAB) has been used to improve the reproducibility for the separation of organic acids [15]. Unfortunately, so far none of them can simultaneously 
provide the improvements in the reproducibility of migration times and reasonable resolution for the entire separation. Although a change in the direction of the EOF by adding cationic surfactants or a suppression of EOF by coating the capillary wall with chemicals [16] have been employed for better resolution, these methods suffer from irreproducible results, longer preparation time and inconvenience.

For a variety of ionic analytes, which have very close EPMs in isocratic conditions, $\mathrm{pH}$ gradient in CZE has been developed for better separation performance. For example, Bocek and co-workers used a three-pole, two-buffer system $[17,18]$ or switched the buffer electrolytes at the column inlet $[19,20]$ to generate a $\mathrm{pH}$ gradient during the separation. Sustacek et al. [21] dynamically modified the $\mathrm{pH}$ of the electrolyte at the inlet of capillary by steady addition of a modifying electrolyte. Furthermore, the addition of divalent metal ions into the running buffer to form complexes with organic anions has been reported to be useful for the separations of organic acids [22].

Alternatively, controlling temperature of the separation system [23] or performing voltage programming [24] has been shown to be useful for the generation of significant changes in viscosity and $\mathrm{pH}$ of the running buffer. Unfortunately, it is not suitable for the separation of organic acids in weak acidic conditions because the EOF is too small. The other disadvantage of these methods is the use of external means to generate the $\mathrm{pH}$ gradient, which may cause disturbance in peak shapes.

Buffer $\mathrm{pH}$ increases at the cathode and decreases at the anode as a result of electrolysis during a run [25]. Bello has developed a model to explain electrolytic modification of the buffer solutions during a capillary electrophoretic run [26]. He concluded that (1) the smaller the volume of the vial, and the higher the electric field strength and the larger the capillary cross-section area, the more significantly the $\mathrm{pH}$ of the buffer changes during a run; and (2) the stronger the buffer capacity, the less significantly the $\mathrm{pH}$ of the buffer changes during a run. Strege and Lagu also showed that the changes in migration times of trypsinogen in nine consecutive runs are due to electrolytic modification of buffer $\mathrm{pH}$ [27].

Therefore it is possible to generate significant $\mathrm{pH}$ changes for better separation results by the mechanisms of electrolytic modification of buffer during a run. This paper is devoted to the possibility for the separation of organic acids in weak acidic conditions in CZE. In this study, better separation results of organic acids obtained from electrolytic modification of buffer solutions in weak acidic conditions in treated capillaries are emphasized. Changes in capillary dimensions, ionic strengths and types of buffer solution, and electric field strengths have been employed to support the dynamic changes in the system during a run.

\section{Experimental}

\subsection{Instrument}

A commercial electrophoresis instrument from Bio-Rad (BioFocus CE 2000, Hercules, CA, USA) was used. Fused-silica capillaries (Polymicro Technologies, Phoenix, AZ, USA) were $38 \mathrm{~cm}$ in length with 50, 75 and $100 \mu \mathrm{m}$ I.D., respectively. At $33 \mathrm{~cm}$ from the injection end, the polyimide coating was burned off to form the detection window. The absorbance was obtained at $225 \mathrm{~nm}$.

\subsection{Materials}

All chemicals were of reagent grade and were obtained from Aldrich (Milwaukee, WI, USA), except that sodium hydroxide was from Fisher (Fair Lawn, NJ, USA). Buffer solutions were 1,5 or 10 $\mathrm{m} M \mathrm{NaH}_{2} \mathrm{PO}_{4}$ (adjusted by $0.1 M \mathrm{H}_{3} \mathrm{PO}_{4}$ to $\mathrm{pH}$ 4.01) or $1 \mathrm{mM} \mathrm{CH}_{3} \mathrm{COOH}$ (adjusted by $0.01 M$ $\mathrm{NaOH}$ to $\mathrm{pH} 4.01)$. The injected concentration of each analyte is $3 \times 10^{-4} \mathrm{M}$. Mesityl oxide was used to measure EOF coefficient.

\subsection{Capillary equilibrium and separation}

The capillaries were pre-equilibrated with $0.1 \mathrm{M}$ $\mathrm{NaOH}$ for 1 day before use for electrophoretic separation. After each run, the capillary was equilibrated with $0.1 \mathrm{M} \mathrm{NaOH}$ via high pressure for $3 \mathrm{~min}$, then the remaining base inside the capillary was washed out with the running buffer via high pressure (100 p.s.i.; 1 p.s.i. $=6894.76 \mathrm{~Pa})$ for 10 s. Analytes were introduced into the capillary by applying a high voltage $(10 \mathrm{kV})$ for $5 \mathrm{~s}$. The separations were 
performed at different voltages in different capillaries as shown in Section 3.

\section{Results and discussion}

\subsection{Choice of the separation conditions}

EOF in CZE is governed by wall $\zeta$ potential of the capillary which is proportional to the net charge (mostly from the dissociation of the silanol group) of the capillary wall. The best known phenomenon of EOF in the fused capillary is its sigmoid relationship with $\mathrm{pH}$ [28]. Therefore, in terms of speed and reproducibility, it is better to perform the separation at higher $\mathrm{pH}$ to obtain more constant and high EOF in CZE. On the other hand, to obtain maximal resolution, as a rule of thumb, it is better to run separation at $\mathrm{pH}$ close to $\mathrm{p} K_{\mathrm{a}}$ values of analytes. Unfortunately, we were unable to separate eight organic acids with $\mathrm{p} K_{\mathrm{a}}$ values between 2 and 7 either at $\mathrm{pH} 6.1$ or $4.01,1 \mathrm{~m} M$ phosphate buffer solutions. The results are similar to those shown in the paper by Zare and co-workers where formic acid and acetic acid could not migrate out at the cathode end at $\mathrm{pH}$ 5.9 [7]. It is therefore necessary to develop a method providing high EOF in weak acidic conditions for high-speed and high-resolution separations of organic acids.

\subsection{Separation of organic acids in a dynamic mode}

Herein, we demonstrated a new method, which is able to dynamically control migration velocities of analytes in weak acidic conditions. In our method, capillaries were simply pre-equilibrated with $0.1 \mathrm{M}$ $\mathrm{NaOH}$, then $\mathrm{NaOH}$ remaining inside the capillary was forced out via high pressure (100 p.s.i.) with running buffers at $\mathrm{pH} 4.01$ for $10 \mathrm{~s}$. The volume flushed via high pressure for $10 \mathrm{~s}$ is sufficient to remove the remaining base inside the capillary since we estimated that the wash volume is more than 10 times the capillary volume. Another fact that proves there is no excess $\mathrm{NaOH}$ left in the liquid phase inside the capillary is the observation of very low current (around $3.8 \mu \mathrm{A}$ ) at $22 \mathrm{kV}$. The values are almost the same as those we got from the equilib- rium conditions. Fig. 1 shows three consecutive separations of eight organic acids via dynamic control mode proposed in this study. Eight organic acids were well separated in $7 \mathrm{~min}$ with very good reproducibility when the applied voltage was set at $22 \mathrm{kV}$. The use of $0.1 M \mathrm{NaOH}$ to equilibrate capillaries for $3 \mathrm{~min}$ is effective to regenerate relatively high EOF compared to the EPM of the analytes, even at such low $\mathrm{pH}$ in CZE. Since the phosphate buffer solution used does not fall into its effective buffering range $\left(\mathrm{p} K_{\mathrm{a}} \pm 1\right)$, the $\mathrm{pH}$ values of the solution in the inlet vial, outlet vial and inside capillary will change due to electrolysis during separation. It is therefore possible to generate local
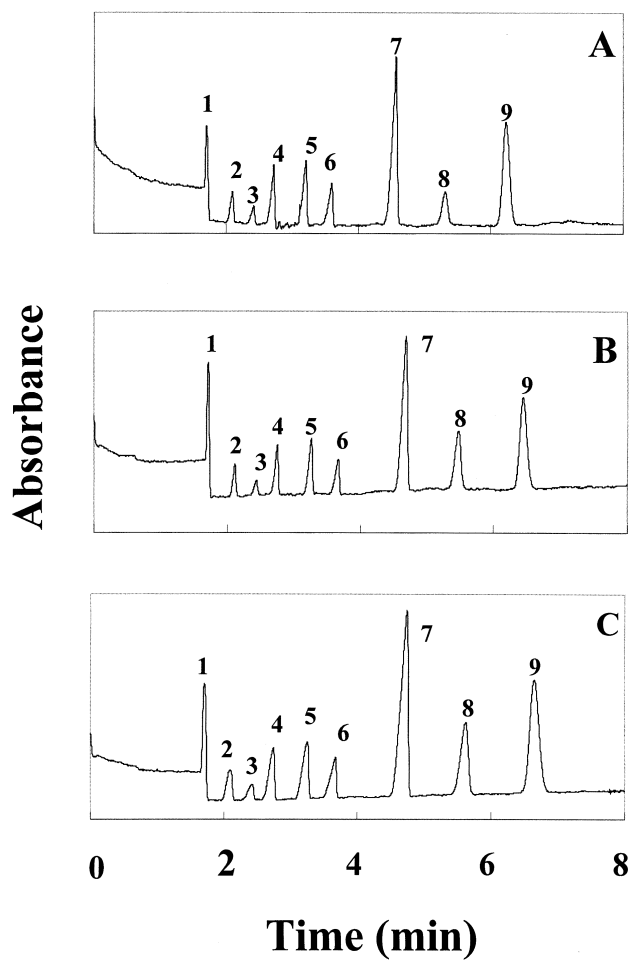

Fig. 1. Three consecutive separations of analytes in $\mathrm{pH} 4.01,1$ $\mathrm{m} M$ phosphate buffer solution at $22 \mathrm{kV}$ via dynamic control mode. The capillary was treated with $0.1 M \mathrm{NaOH}$ for $3 \mathrm{~min}$, then flushed with $1 \mathrm{~m} M$ phosphate buffer solution via high pressure for 10 s. Column: $75 \mu \mathrm{m}$ I.D. $\times 365 \mu \mathrm{m}$ O.D.; $38 \mathrm{~cm}$ total length, 33 $\mathrm{cm}$ effective length. Detection wavelength, $225 \mathrm{~nm}$. Peak identities: (1) mesityl oxide; (2) $p$-aminobenzoic acid; (3) $p$-hydroxybenzoic acid; (4) $p$-toluic acid; (5) benzoic acid; (6) $o$-toluic acid; (7) $m$-nitrobenzoic acid; (8) $o$-nitrobenzoic acid; (9) citraconic acid. 
migration velocities inside the capillary. To keep more reproducible results, it is also important to refill with the buffer solution after each run. In comparison with another method, wherein the direction of EOF is reversed by adding cationic surfactants, this method provides the benefit of the enhancement of the resolution. When CTAB [8] is used to obtain the same direction between EOF and EPM of the analytes, worse resolution in CZE is predicted according to the following equation [29]:

$R=0.177\left(m_{\text {eff } 1}-m_{\text {eff } 2}\right)\left[V / D\left(m_{\text {av }}+m_{\text {eo }}\right)\right]^{1 / 2}$

where, $R$ is the resolution, $V$ is the applied voltage, $D$ is the diffusion coefficient, $m_{\mathrm{av}}$ is the average mobility of the two analytes and $m_{\text {eff } 1}, m_{\text {eff } 2}$ and $m_{\mathrm{eo}}$ are the effective mobilities of two analytes and the EOF coefficient, respectively. According to this equation, it is obvious that our method is able to provide better resolution since $m_{\mathrm{av}}+m_{\mathrm{eo}}$ in our study is smaller due to the opposite direction between EOF and EPM.

\subsection{Separation performance}

\subsubsection{Effects of the electric field strength}

Tables 1-4 show three consecutive separation results at different applied voltages, 10, 14, 18 and $22 \mathrm{kV}$, respectively. All standard deviations are less

Table 1

EOF coefficient $\left(m_{\mathrm{eo}}\right)$ and EPM $\left(m_{\mathrm{ep}}\right)$ of the analytes via dynamic control as the applied voltage was set at $22 \mathrm{kV}$

\begin{tabular}{|c|c|c|c|c|c|}
\hline \multirow[t]{2}{*}{ Analytes } & \multicolumn{5}{|c|}{$m_{\mathrm{eo}}\left(\times 10^{-4} \mathrm{~cm}^{2} / \mathrm{V} \mathrm{s}\right)^{\mathrm{a}}$} \\
\hline & 1 & 2 & 3 & Mean & S.D. \\
\hline \multirow[t]{2}{*}{ Mesityl oxide } & \multicolumn{5}{|c|}{$-m_{\mathrm{ep}}\left(\times 10^{-4} \mathrm{~cm}^{2} / \mathrm{V} \mathrm{s}\right)$} \\
\hline & 5.56 & 5.52 & 5.59 & 5.56 & 0.04 \\
\hline$p$-Aminobenzoic acid & 1.03 & 1.04 & 1.04 & 1.04 & 0.01 \\
\hline$p$-Hydroxybenzoic acid & 1.65 & 1.65 & 1.66 & 1.65 & 0.01 \\
\hline$p$-Toluic acid & 2.10 & 2.08 & 2.10 & 2.09 & 0.01 \\
\hline Benzoic acid & 2.64 & 2.62 & 2.63 & 2.63 & 0.01 \\
\hline$o$-Toluic acid & 2.97 & 2.93 & 2.95 & 2.95 & 0.02 \\
\hline$m$-Nitrobenzoic acid & 3.56 & 3.50 & 3.51 & 3.52 & 0.03 \\
\hline$o$-Nitrobenzoic acid & 3.87 & 3.79 & 3.80 & 3.82 & 0.04 \\
\hline Citraconic acid & 4.13 & 4.05 & 4.07 & 4.08 & 0.04 \\
\hline
\end{tabular}

${ }^{\mathrm{a}} \mathrm{EOF}$ coefficient is positive as EOF is toward the cathode.

${ }^{\mathrm{b}}$ Standard deviation.
Table 2

EOF coefficient $\left(m_{\mathrm{eo}}\right)$ and EPM $\left(m_{\mathrm{ep}}\right)$ of analytes via dynamic control as the applied voltage was set at $18 \mathrm{kV}$

\begin{tabular}{|c|c|c|c|c|c|}
\hline \multirow[t]{2}{*}{ Analytes } & \multicolumn{5}{|c|}{$m_{\mathrm{eo}}\left(\times 10^{-4} \mathrm{~cm}^{2} / \mathrm{V} \mathrm{s}\right)^{\mathrm{a}}$} \\
\hline & 1 & 2 & 3 & Mean & S.D. \\
\hline \multirow[t]{2}{*}{ Mesityl oxide } & \multicolumn{5}{|c|}{$-m_{\mathrm{ep}}\left(\times 10^{-4} \mathrm{~cm}^{2} / \mathrm{V} \mathrm{s}\right)$} \\
\hline & 5.43 & 5.43 & 5.33 & 5.40 & 0.06 \\
\hline$p$-Aminobenzoic acid & 1.46 & 1.46 & 1.40 & 1.44 & 0.04 \\
\hline p-Hydroxybenzoic acid & 1.94 & 1.95 & 1.87 & 1.92 & 0.04 \\
\hline$p$-Toluic acid & 2.31 & 2.33 & 2.24 & 2.29 & 0.05 \\
\hline Benzoic acid & 2.76 & 2.79 & 2.69 & 2.75 & 0.05 \\
\hline$o$-Toluic acid & 2.93 & 2.94 & 2.85 & 2.91 & 0.05 \\
\hline$m$-Nitrobenzoic acid & 3.38 & 3.41 & 3.31 & 3.37 & 0.05 \\
\hline$o$-Nitrobenzoic acid & 3.62 & 3.65 & 3.55 & 3.61 & 0.05 \\
\hline Citraconic acid & 3.94 & 3.97 & 3.87 & 3.93 & 0.05 \\
\hline
\end{tabular}

${ }^{a}$ EOF coefficient is positive as EOF is toward the cathode.

${ }^{\mathrm{b}}$ Standard deviation.

than 0.09 meaning that our new method provides reasonably reproducible performance. It is understandable that reproducibility becomes worse when migration time becomes longer. This is especially true for strong acids when the separation was performed at lower applied voltages. Larger variance (dispersion) may be one of the reasons for slight irreproducibility since variance, if resulting from diffusion, becomes significant as migration times are longer. To further prove the dependence of the changes in EPM of analytes and EOF on separation

Table 3

EOF coefficient $\left(m_{\mathrm{ep}}\right)$ and EPM $\left(m_{\mathrm{ep}}\right)$ of analytes via dynamic control as the applied voltage was set at $14 \mathrm{kV}$

\begin{tabular}{|c|c|c|c|c|c|}
\hline \multirow[t]{2}{*}{ Analytes } & \multicolumn{5}{|c|}{$m_{\text {eо }}\left(\times 10^{-4} \mathrm{~cm}^{2} / \mathrm{V} \mathrm{s}\right)^{\mathrm{a}}$} \\
\hline & 1 & 2 & 3 & Mean & S.D. \\
\hline \multirow[t]{2}{*}{ Mesityl oxide } & \multicolumn{5}{|c|}{$-m_{\mathrm{ep}}\left(\times 10^{-4} \mathrm{~cm}^{2} / \mathrm{V} \mathrm{s}\right)$} \\
\hline & 5.47 & 5.57 & 5.41 & 5.48 & 0.08 \\
\hline$p$-Aminobenzoic acid & 1.06 & 1.20 & 1.12 & 1.13 & 0.07 \\
\hline$p$-Hydroxybenzoic acid & 1.66 & 1.79 & 1.64 & 1.70 & 0.08 \\
\hline$p$-Toluic acid & 2.11 & 2.27 & 2.22 & 2.20 & 0.08 \\
\hline Benzoic acid & 2.65 & 2.80 & 2.66 & 2.70 & 0.08 \\
\hline$o$-Toluic acid & 2.98 & 3.09 & 2.96 & 3.01 & 0.07 \\
\hline$m$-Nitrobenzoic acid & 3.56 & 3.64 & 3.50 & 3.57 & 0.07 \\
\hline$o$-Nitrobenzoic acid & 3.87 & 3.93 & 3.78 & 3.86 & 0.08 \\
\hline Citraconic acid & 4.14 & 4.22 & 4.05 & 4.14 & 0.09 \\
\hline
\end{tabular}

${ }^{a} \mathrm{EOF}$ coefficient is positive as EOF is toward the cathode.

${ }^{\mathrm{b}}$ Standard deviation. 
Table 4

EOF coefficient $\left(m_{\mathrm{eo}}\right)$ and EPM $\left(m_{\mathrm{ep}}\right)$ of analytes via dynamic control as the applied voltage was set at $10 \mathrm{kV}$

\begin{tabular}{|c|c|c|c|c|c|}
\hline \multirow[t]{2}{*}{ Analytes } & \multicolumn{5}{|c|}{$m_{\mathrm{eo}}\left(\times 10^{-4} \mathrm{~cm}^{2} / \mathrm{V} \mathrm{s}\right)^{\mathrm{a}}$} \\
\hline & 1 & 2 & 3 & Mean & S.D. \\
\hline \multirow[t]{2}{*}{ Mesityl oxide } & \multicolumn{5}{|c|}{$-m_{\mathrm{ep}}\left(\times 10^{-4} \mathrm{~cm}^{2} / \mathrm{V} \mathrm{s}\right)$} \\
\hline & 5.24 & 5.32 & 5.36 & 5.31 & 0.06 \\
\hline$p$-Aminobenzoic acid & 0.99 & 1.02 & 1.06 & 1.02 & 0.04 \\
\hline$p$-Hydroxybenzoic acid & 1.60 & 1.64 & 1.65 & 1.63 & 0.03 \\
\hline$p$-Toluic acid & 2.07 & 2.11 & 2.13 & 2.10 & 0.03 \\
\hline Benzoic acid & 2.61 & 2.67 & 2.69 & 2.66 & 0.04 \\
\hline$o$-Toluic acid & 2.97 & 3.06 & 3.04 & 3.03 & 0.05 \\
\hline$m$-Nitrobenzoic acid & 3.61 & 3.72 & 3.66 & 3.66 & 0.06 \\
\hline$o$-Nitrobenzoic acid & 3.97 & 4.09 & 3.99 & 4.02 & 0.06 \\
\hline Citraconic acid & 4.24 & 4.36 & 4.27 & 4.29 & 0.06 \\
\hline
\end{tabular}

${ }^{\mathrm{a}} \mathrm{EOF}$ coefficient is positive as EOF is toward the cathode.

${ }^{\mathrm{b}}$ Standard deviation.

time, Fig. 2 was plotted from the results shown in Tables 1-4. The higher values of EPM of stronger acids and EOF at $22 \mathrm{kV}$ compared to those obtained at lower applied voltages may result from the decrease in viscosity of the running buffer at higher applied voltages. The relatively lower EOF and EPM of analytes obtained at equilibrium conditions than those obtained at dynamic conditions cannot only explain the existence of significant amounts of negatively charged species in the capillary surface, but also show the occurrence of the changes in local $\mathrm{pH}$ and EOF. Electrolysis and the change in the capillary surface, which are time dependent, account for the existence of a dynamic separation system. Therefore, the changes of $\mathrm{pH}$ inside the capillary and in the inlet and outlet vials become more significant as migration times increase. According to Bello's model, we know the changing rate of buffer $\mathrm{pH}$ is faster at higher electric field strength [26]. The $\mathrm{pH}$ of solution inside the capillary close to the cathode end should be higher than that at the anode end; and the difference between the two ends should be more significant at higher electric field strength after a run. For example, the $\mathrm{pH}$ values measured in the inlet vial and outlet vials were 3.97 and 4.26 at $15 \mathrm{kV}$, and 3.87 and 4.36 at $22 \mathrm{kV}$, respectively, after $10 \mathrm{~min}$. There is no doubt that local $\mathrm{pH}$ changes exist inside the capillary. We also believe that these changes occur in time and space inside the capillary during separation. For stronger acids, they migrate slowly.

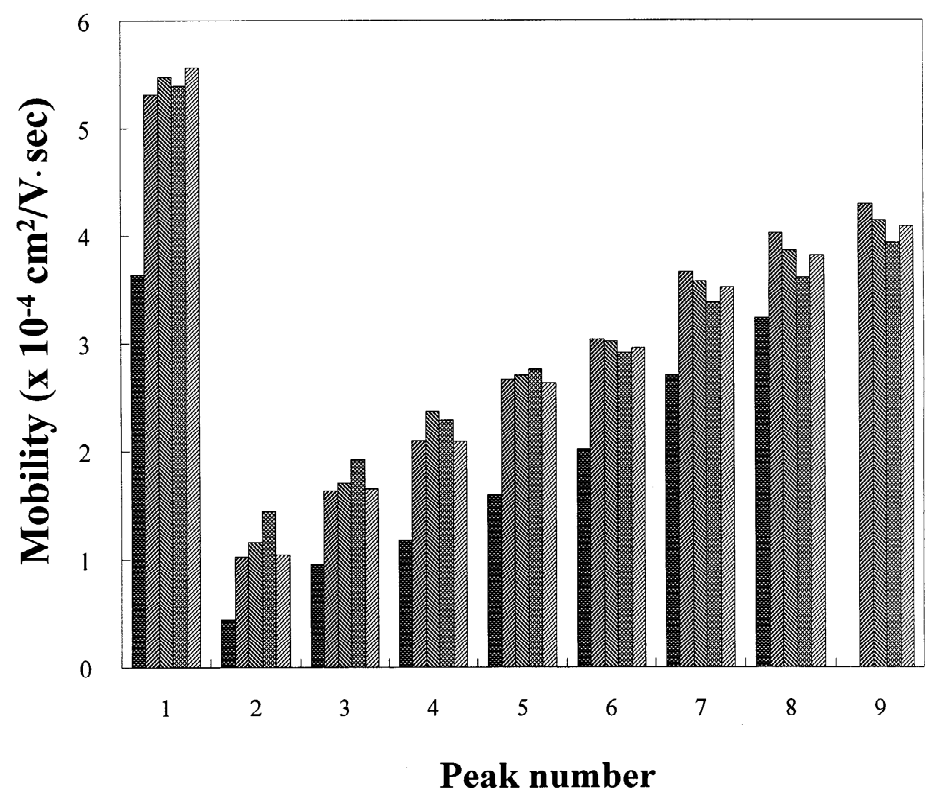

Fig. 2. Comparison of EOF coefficients and EPM of analytes from the results shown in Tables 1-4 and in equilibrium (no treatment of the capillary with $\mathrm{NaOH}$ ). Each number represents the same analyte as that assigned in Fig. 1. Heavy-crossed bar, in equilibrium; light-left-shaded bar, Table 1; light-crossed bar, Table 2; heavy-right-shaded bar, Table 3; heavy-left-shaded bar, Table 4. 
Therefore there are more chances for strong acids to face solution with higher local $\mathrm{pH}$ values. It may explain why average EPMs of stronger acids obtained at lower applied voltages are slightly higher than those at higher applied voltages. Time-dependent desorption of surface-charged species is another factor governing EOF, which needs to be taken into account. Local EOF close to the anode end decreases due to decreases in $\mathrm{pH}$ and negatively charged surface density of the capillary during a run. At the cathode end, however, local EOF is determined by the increase in local $\mathrm{pH}$ and decrease in negatively charged surface density of the capillary. Since the effect of the change in $\mathrm{pH}$ on EOF is not significant in $10 \mathrm{~min}$, the change in surface-charged density should dominate the changes in EOF. For very long separation times, more significant changes in EPM and EOF are possible. This may explain why we are unable to detect strong polyprotic acids, such as fumaric acid, although average EOF values $\left(\mathrm{cm}^{2} / \mathrm{V}\right.$ s) were $5.56 \times 10^{-4}$ at $22 \mathrm{kV}, 5.39 \times 10^{-4}$ at $18 \mathrm{kV}$, $5.48 \times 10^{-4}$ at $14 \mathrm{kV}$, and $5.31 \times 10^{-4}$ at $10 \mathrm{kV}$, respectively. From the measurement of EOF (3.68 $\times$ $10^{-4} \mathrm{~cm}^{2} / \mathrm{V}$ s) under equilibrium conditions, the smallest local EOF should not be less than $3.68 \times$ $10^{-4} \mathrm{~cm}^{2} / \mathrm{V} \mathrm{s}$. Unfortunately, this is not true because decreases in local $\mathrm{pH}$ and negatively charged surface species at the inlet end become more significant when migration times are very long. Therefore, a much longer migration time for stronger acids is observed than that predicted from theory. The reason is that the average EOF obtained from the use of mesityl oxide as a neutral marker only correlates with the changes in the system in a short period of time. On the other hand, for weaker acids, they migrate faster. Weak acids have less chance to face larger changes in local $\mathrm{pH}$ and EOF. Since their $\mathrm{p} K_{\mathrm{a}}$ values are close to buffer $\mathrm{pH}$, slight changes in $\mathrm{pH}$ can generate more significant effects on the changes in degree of dissociation of weak acids. Thus, the local changes in $\mathrm{pH}$ should account for the high separation resolution of the acids. For example, the change from $\mathrm{pH} 4.01$ to 4.10 can cause increases in the degrees of dissociation, 0.024 for $p$-aminobenzoic acid $\left(\mathrm{p} K_{\mathrm{a}}=4.853\right)$ and 0.050 for benzoic acid $\left(\mathrm{p} K_{\mathrm{a}}=4.203\right)$, respectively.

Table 5 shows the separations of organic acids in three different capillaries. Relatively larger variation
Table 5

Reproducibility of migration times of nine analytes at $22 \mathrm{kV}$ in three different capillaries

\begin{tabular}{llll}
\hline Analytes & \multicolumn{3}{l}{ Migration time (mean (S.D.); min) ${ }^{\mathrm{a}}$} \\
\cline { 2 - 4 } & Capillary 1 & Capillary 2 & Capillary 3 \\
\hline Mesityl oxide & $1.71(0.01)$ & $1.97(0.01)$ & $1.71(0.01)$ \\
$p$-Aminobenzoic acid & $2.10(0.01)$ & $2.20(0.03)$ & $1.93(0.03)$ \\
$p$-Hydroxybenzoic acid & $2.43(0.02)$ & $2.45(0.04)$ & $2.25(0.04)$ \\
$p$-Toluic acid & $2.74(0.02)$ & $2.65(0.06)$ & $2.40(0.05)$ \\
Benzoic acid & $3.25(0.02)$ & $3.05(0.10)$ & $2.75(0.06)$ \\
$o$-Toluic acid & $3.65(0.03)$ & $3.52(0.12)$ & $3.15(0.05)$ \\
$m$-Nitrobenzoic acid & $4.71(0.06)$ & $4.80(0.15)$ & $4.25(0.07)$ \\
$o$-Nitrobenzoic acid & $5.48(0.11)$ & $5.82(0.17)$ & $5.47(0.09)$ \\
Citraconic acid & $6.45(0.15)$ & $7.45(0.22)$ & $6.32(0.11)$ \\
\hline
\end{tabular}

${ }^{\mathrm{a}}$ Three different separation results.

in migration times observed among different capillaries compared to those from intra-runs (same capillary) possibly results from slight variations of capillary length and capillary properties. Day-to-day variation is not a problem because the capillaries were equilibrated overnight after runs.

\subsubsection{Effects of other factors}

To further support our new technique, it is useful to test the effects of capillary dimensions, and ionic strengths and types of buffer solution on the separations of organic acids. Tables 6 and 7 show the changes in buffer $\mathrm{pH}$ at the cathode and migration times of nine analytes in capillaries with different dimensions, ionic strengths and types of buffer solutions. The increases of $\mathrm{pH}$ at the cathode in 10 min are as those expected from Bello's model. Relatively constant buffer $\mathrm{pH}$ obtained after a run in the acetate system is due to its better buffer capacity $\left(\mathrm{p} K_{\mathrm{a}}=4.75\right)$. Higher conductivity in larger capillaries and higher ionic strengths, accounts for faster increase in the rate of buffer $\mathrm{pH}$ at the cathode. The results that stronger acids [ $o$-nitrobenzoic acid and citraconic acid (10 $\mathrm{mM})$ and citroconic acid $(5 \mathrm{mM})$ ] were not detected in the phosphate system support the existence of dynamic changes. A buffer with higher ionic strength can cause faster decrease in negatively charged species in the capillary, in turn causing dramatic decrease in EOF. Higher local EPM of stronger acids obtained in $10 \mathrm{~m} M$ phosphate 
Table 6

Buffer $\mathrm{pH}$ at the cathode after separation at $22 \mathrm{kV}$ for 10 min under different conditions

\begin{tabular}{lcll}
\hline Conditions & Capillary I.D. $(\mu \mathrm{m})$ & Buffer solutions & $\mathrm{pH}^{\mathrm{a}}$ \\
\hline A & 75 & acetate, $1 \mathrm{~m} M$ & $4.07 \pm 0.02$ \\
B & 75 & phosphate, $10 \mathrm{~m} M$ & $4.75 \pm 0.10$ \\
C & 75 & phosphate, $5 \mathrm{~m} M$ & $4.51 \pm 0.07$ \\
D & 75 & phosphate, $1 \mathrm{~m} M$ & $4.32 \pm 0.03$ \\
E & 50 & phosphate, $1 \mathrm{~m} M$ & $4.23 \pm 0.03$ \\
F & 100 & phosphate, $1 \mathrm{~m} M$ & $4.40 \pm 0.09$ \\
\hline
\end{tabular}

${ }^{\mathrm{a}}$ Original $\mathrm{pH}$ is 4.01 ; means of three different results.

(more significant increase in $\mathrm{pH}$ at the cathode end) is another reason for this observation. Relatively shorter migration times obtained from the use of larger capillaries support the importance of the role of negatively charged capillary surface species on EOF. Capillaries with larger cross-section area have more negatively charged species and less area/volume ratio. It therefore takes more time for the capillary wall to reach equilibrium. In addition, the slight Joule heat may also account for the faster migration velocity in larger capillaries. The observation that citraconic acid moves much faster and very closely to $o$-nitrobenzoic acid in the acetate system can explain the role of the change of $\mathrm{pH}$ on the resolution results. It is not as efficient to generate dissociation of citraconic acid ( $\mathrm{p} K_{\mathrm{a}}$ values, 2.15 and $6.15)$ in acetate system ( $\mathrm{pH} 4.07$ at the cathode) as that in the phosphate system $(\mathrm{pH} 4.32$ at the cathode).

\section{Conclusion}

In comparison with results obtained from other methods, such as self-regulating dynamic control, voltage programming, external electric field and other $\mathrm{pH}$ gradient methods, this method, so far, is the simplest one and provides the best performance for the separation of organic acids. Since there is no need for the use of other chemicals and any external equipment, this method is free from several problems occurred in other methods. For example, chemical interference in self-regulating mode, dispersion in external electrical field and optical noise in $\mathrm{pH}$

Table 7

Migration times of analytes obtained in different conditions

\begin{tabular}{|c|c|c|c|c|c|c|}
\hline \multirow[t]{2}{*}{ Analytes } & \multicolumn{6}{|c|}{ Migration times (mean (S.D.); min) ${ }^{\mathrm{a}}$} \\
\hline & $\mathrm{A}^{\mathrm{b}}$ & $\mathrm{B}$ & $\mathrm{C}$ & $\mathrm{D}$ & $\mathrm{E}$ & $\mathrm{F}$ \\
\hline Mesityl oxide & $2.18(0.04)$ & $2.19(0.03)$ & $2.10(0.03)$ & $1.71(0.01)$ & $1.88(0.02)$ & $1.68(0.04)$ \\
\hline$p$-Aminobenzoic acid & $2.47(0.04)$ & $2.51(0.03)$ & $2.38(0.05)$ & $1.97(0.01)$ & $2.26(0.02)$ & $1.89(0.03)$ \\
\hline$p$-Hydroxybenzoic acid & $2.76(0.05)$ & $3.03(0.04)$ & $2.70(0.06)$ & $2.05(0.01)$ & $2.64(0.02)$ & $2.11(0.05)$ \\
\hline$p$-Toluic acid & $3.05(0.07)$ & $3.25(0.04)$ & $3.00(0.05)$ & $2.36(0.01)$ & $2.96(0.02)$ & $2.27(0.04)$ \\
\hline Benzoic acid & $3.55(0.09)$ & $3.94(0.06)$ & $3.51(0.06)$ & $2.70(0.02)$ & $3.53(0.05)$ & $2.53(0.02)$ \\
\hline$o$-Toluic acid & $4.13(0.09)$ & $4.71(0.05)$ & $4.20(0.05)$ & $3.17(0.04)$ & $4.17(0.09)$ & $2.86(0.02)$ \\
\hline$m$-Nitrobenzoic acid & $5.54(0.11)$ & $9.15(0 . .13)$ & $6.99(0.12)$ & $4.37(0.09)$ & $5.87(0.11)$ & $3.75(0.03)$ \\
\hline$o$-Nitrobenzoic acid & $7.02(0.12)$ & N.D. & $15.45(0.35)$ & $5.85(0.12)$ & $8.01(0.25)$ & $5.02(0.14)$ \\
\hline Citraconic acid & $7.15(0.12)$ & N.D. & N.D. & $7.01(0.15)$ & $9.85(0.35)$ & $5.67(0.25)$ \\
\hline
\end{tabular}

${ }^{\mathrm{a}}$ Three different separation results.

${ }^{\mathrm{b}}$ Letters A-F as shown in Table 6.

${ }^{\mathrm{c}}$ Not detected. 
gradient generated by two different electrolytes via a mechanical pump. Lastly, this method offers the advantage of high throughput since the separation is faster and there is no need for very long equilibrium time.

One of the most important features of this new technique is the possible application for the separations of many analytes, such as acids, amines and peptides via any commercial CE instrument. In addition, the suggested valuable approach for the separation of organic acids provides advantages of high speed, good reproducibility, high resolution and simplicity. Changes in EOF and EPM of analytes in real-time scales will be studied by using the similar setup shown by Yeung's group [30] and Nilsson's group [31]. It may be useful for us to further identify more suitable separation mechanisms for this dynamic mode.

\section{Acknowledgements}

This work was supported by grants from the Department of Chemistry, National Taiwan University and the School of Arts and Science, National Taiwan University.

\section{References}

[1] J.W. Jorgenson, K.D. Lukas, Science (Washington, DC) 222 (1983) 266.

[2] E.B. Walker, J.C. Walker, S.E. Zaugg, R. Davidson, J. Chromatogr. A 745 (1996) 111.

[3] K.R. Skelsey, M.M. Bushey, J. Chromatogr. Sci. 34 (1996) 85 .
[4] S.J. Gluck, K.P. Steele, M.H. Benko, J. Chromatogr. A 745 (1996) 117.

[5] V. Levi, T. Wehr, K. Talmadge, M. Zhu, Am. Lab. 25 (1993) 29.

[6] M. Jimidar, Q. Yang, J. Smeyer-Verbeke, D.L. Massart, Trends Anal. Chem. 15 (1996) 91.

[7] X. Huan, J.A. Luckey, M.J. Gordon, R.N. Zare, Anal. Chem. 61 (1989) 766.

[8] H.-T. Chang, E.S. Yeung, J. Chromatogr. 602 (1992) 65.

[9] T. Okada, J. Chromatogr. A 695 (1995) 309.

[10] X. Ren, Y. Shen, M. Lee, J. Chromatogr. A 741 (1996) 115.

[11] T. Kaneta, S. Tanaka, H. Yoshida, J. Chromatogr. 538 (1991) 385.

[12] S. Fujiwara, S. Honda, Anal. Chem. 58 (1986) 1811.

[13] C.T. Wu, C.S. Lee, C.J. Miller, Anal. Chem. 64 (1992) 2310.

[14] J.C. Helmer, R.L. Chien, Anal. Chem. 63 (1991) 1354.

[15] H.-T. Chang, E.S. Yeung, Anal. Chem. 65 (1993) 650.

[16] A.M. Desbene, C.J. Morin, N.L. Mofaddel, R.S. Groult, J. Chromatogr. A 716 (1995) 279.

[17] P. Gebaur, M. Deml, J. Pospichal, P. Bocek, Electrophoresis 11 (1990) 724.

[18] M. Deml, J. Pospichal, J. Sudor, P. Bocek, J. Chromatogr. 470 (1989) 43.

[19] F. Foret, S. Fanali, P. Bocek, J. Chromatogr. 516 (1990) 219.

[20] J. Sudor, J. Pospichal, M. Deml, P. Bocek, J. Chromatogr. 545 (1991) 331

[21] V. Sustacek, F. Foret, P. Bocek, J. Chromatogr. 480 (1989) 271.

[22] M. Chiari, N.D. Orto, L. Casella, J. Chromatogr. A 745 (1996) 93.

[23] C.W. Whang, E.S. Yeung, Anal. Chem. 64 (1992) 502.

[24] H.-T. Chang, E.S. Yeung, J. Chromatogr. 632 (1993) 149.

[25] T. Zhu, Y.-L. Sun, C.-X. Zhang, D.-K. Ling, Z.-P. Sun, J. High Resolut. Chromatogr. 17 (1994) 563.

[26] M.S. Bello, J. Chromatogr. A 744 (1996) 81.

[27] M.K. Strege, A.L. Lagu, J. Liq. Chromatogr. 16 (1993) 51.

[28] W.J. Lambert, D.L. Middleton, Anal. Chem. 62 (1990) 1585.

[29] J.W. Jorgenson, K.D. Luckas, Anal. Chem. 53 (1981) 1298.

[30] J. Preisler, E.S. Yeung, Anal. Chem. 68 (1996) 2885.

[31] J. Johansson, D.T. Witte, M. Larson, S. Nilsson, Anal. Chem. 68 (1996) 2766 